\title{
Transcatheter Therapies for Tricuspid Valve Failure
}

\author{
Zakaria Jalal, MD ${ }^{1}$, Rachid Zegdi, MD, $\mathrm{PhD}^{2-4}$, Alexander Lauten, MD ${ }^{5}$, Patel Mehul, MD', \\ Younes Boudjemline, MD, PhD ${ }^{1,4,6 *}$ \\ Rachid Zegdi and Alexander Lauten have contributed equally to the writing of this paper. \\ ${ }^{1}$ Centre de Référence Malformations Cardiaques Congénitales Complexes - M3C, Hôpital Necker-Enfants Malades, Hôpital Européen \\ Georges Pompidou, Assistance Publique des Hôpitaux de Paris, Unité médico-chirurgicale, Paris, France \\ ${ }^{2}$ Inserm U970, Faculté de Necker, Paris, France \\ ${ }^{3}$ Service de Chirurgie Cardiovasculaire, Hôpital Européen Georges Pompidou, AP-HP, Paris, France \\ ${ }^{4}$ Université Paris Descartes, Sorbonne Paris Cité, Paris, France \\ ${ }^{5}$ Klinik für Innere Medizin 1, Kardiologie, Erlanger Allee 101, 07743 Jena, Germany \\ ${ }^{6}$ EA 7328 FETUS, Faculté de Necker, Paris, France
}

\begin{abstract}
Tricuspid valve failure with low output state is a growing problem in the management of structural heart disease and stage $D$ heart failure. Severe tricuspid valve disease either due to congenital or acquired etiology constitutes high risk for palliative or definitive surgical correction. Limited progress is noted so far on the evolution of durable surgical techniques on tricuspid valve disease and spiraling down refractory right heart failure continues to be the Achilles heel in the management. Over the last decade, transcatheter therapies for the management of aortic and pulmonary valves have expanded the therapeutic options for patients deemed at high risk for conventional surgery. The interventional therapies to manage tricuspid valve failure have mostly been a surrogate use of established therapies for other valves. The numerous interventional strategies used on failing tricuspid valve include percutaneous tricuspid valvuloplasty, percutaneous valve in valve, valve-in-ring implantation, and orthotopic/ heterotopic valve implantation using commercially available "off-label" device or dedicated custom-made devices. This review focuses on the different percutaneous approaches and devices that have evolved for the management of tricuspid valve failure with varying anatomical substrates such as native tricuspid valves, annuloplasty rings or bioprosthesis.
\end{abstract}

Copyright $\odot 2015$ Science International Corp.

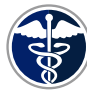

Fax +1 2037853346

E-Mail: jshd@scienceinternational.org

http://structuralheartdisease.org/
(C) 2015 Journal of Structural Heart Disease Published by Science International Corp. ISSN 2326-4004

Accessible online at:

http://structuralheartdisease.org/
Key Words:

Transcatheter - Tricuspid valve - Congenital heart diseases • Tricuspid stenosis • Tricuspid insufficiency

\section{Introduction}

A variety of congenital and acquired etiologies affect the tricuspid valve. While congenital lesions such as tricuspid valve dysplasia or Ebstein's anomaly cause organic involvement of the tricuspid valve apparatus, acquired lesions may be function with less obvious structural abnormality other than annular dilation, most commonly due to pulmonary hypertension or any other etiology causing severe right ventricular dilatation [1-3]. Once considered a dispensable valve, when tricuspid valve stenosis and/or regurgitation are severe, cardiac output decreases and patients develop spiralling down symptoms of right heart failure with congestive hepatosplenomegaly, peripheral oedema and cardiac cachexia. A wide variety of tricuspid valve surgeries such as valve repair with or without annuloplasty and even valve replacement have produced just satisfactory results mostly due to the high operative mortality of up to $22 \%$ in such patients deemed as very high-risk for perioperative events [2-4].

*Corresponding Author:

Younes Boudjemline, MD, PhD

Hôpital Necker Enfants Malades

Cardiologie Pédiatrique, 75015 Paris Cedex, France

Phone: +00331 444943 57; Fax: +00331 4449 5724; Email: younes.boudjemline@nck.aphp.fr 


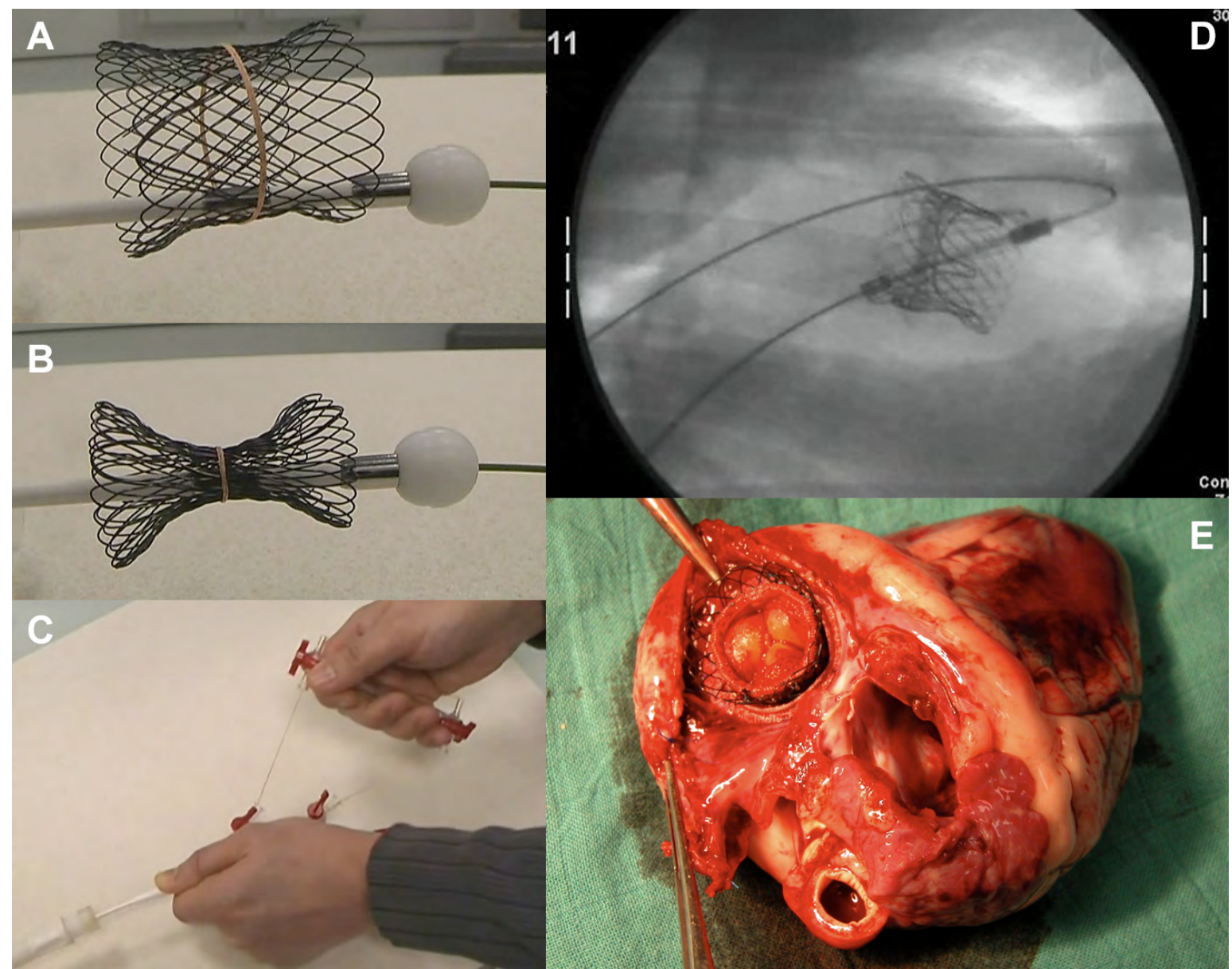

Figure 1. Repositionable valved stent (Zegdi et al. réf 11). A, B and C. Representation of the principle of compression-relaxation of the valved stent. After deployment of the nitinol self-expandable device (A), the stent can be reversibly compressed (B) by exerting traction on the encircling suture through a proximal handle (C). D. Fluoroscopy, positioning of the valved stent within a tricuspid bioprosthetic valve. E. Macroscopic posterior view of the heart showing excellent positioning of the valved stented inside the failed tricuspid bioprosthesis.

Moreover secondary tricuspid valve disease with right ventricular failure is emerging as an Achilles heel for the management of a vast population of patients with severe left sided heart failure, requiring assist devices.

Over the last decade, transcatheter aortic and pulmonary valve implantation has revolutionized the therapeutic options for patients at high risk for conventional surgery [5-8]. There has been growing interest in the field of interventional cardiology to percutaneously treat dysfunctional tricuspid valves. Although the data is less robust compared with transcatheter pulmonary or aortic valve replacement, several experimental and clinically useful interven- tions to treat tricuspid valve dysfunction in various anatomical settings such as native tricuspid valves, annuloplasty rings or bioprosthesis have been described. In this review, we lay emphasis on different strategies and devices developed so far, which may serve as a useful platform for transcatheter therapy for tricuspid valve failure.

\section{Percutaneous Treatment of Degenerated Tricuspid Bioprosthetic Valves: Valve-in-Valve Technique}

Bioprosthetic cardiac valves are usually preferred in young patients due to reduced thromboembol- 


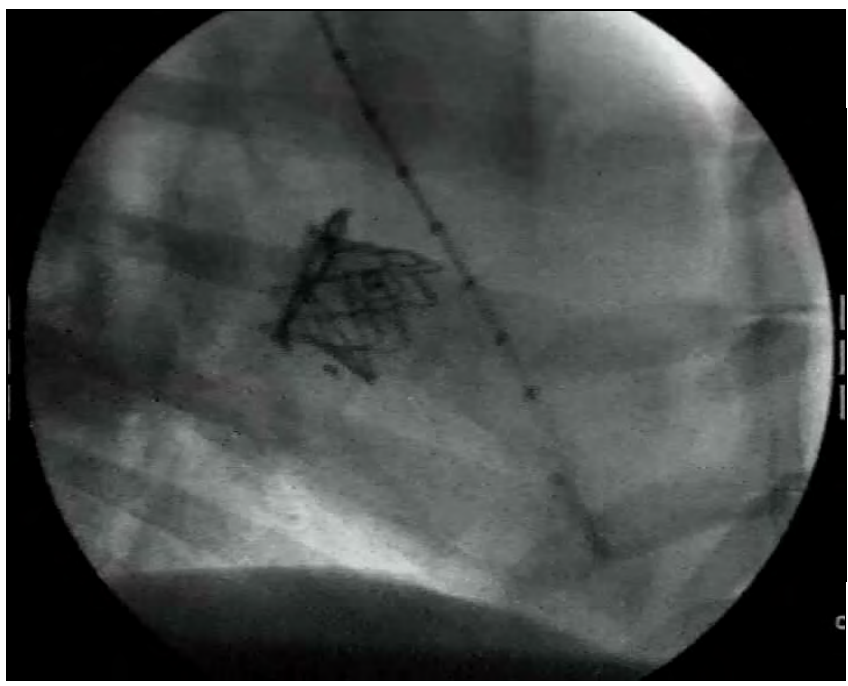

Video 1. Angiogram showing the valve in valve concept in mitral position in a sheep. A bioprosthetic valve (Mosaic, Medtronic) has been surgically placed. A Melody valve has been thereafter placed inside the surgical valve used as a landing zone. (Boudjemline et al, Eur Heart J. 2005;26:2013-7)

ic risk and the need for long-term anticoagulation therapy as required with mechanical prostheses. However all bioprosthetic valves eventually fail over time with progressive age induced degeneration. Repeat sternotomy in such patients carries a high risk of morbidity and mortality. Transcatheter valve-in-valve implantation has emerged as a promising treatment option for degenerated bioprosthetic heart valves in these multi-operated high-risk patients and has been described for failing bioprosthetic valves in all four cardiac locations [9].

\section{Evolution}

In an early preclinical study, Boudjemline et al. [10] were the first to evaluate the proof of concept of mitral valve-in-valve treatment in a sheep model. A bovine jugular valve was mounted on a stent and successfully implanted off-pump through a transatrial miniinvasive approach in 6 sheep (Video 1 and Video 2). In a subsequent animal study, Zegdi et al. [11] reported the successful implantation of a repositionable valved stent (porcine aortic valve sutured on a nitinol self expandable stent) in tricuspid bioprosthetic valves. The originality of the delivery system consisted of the pos-

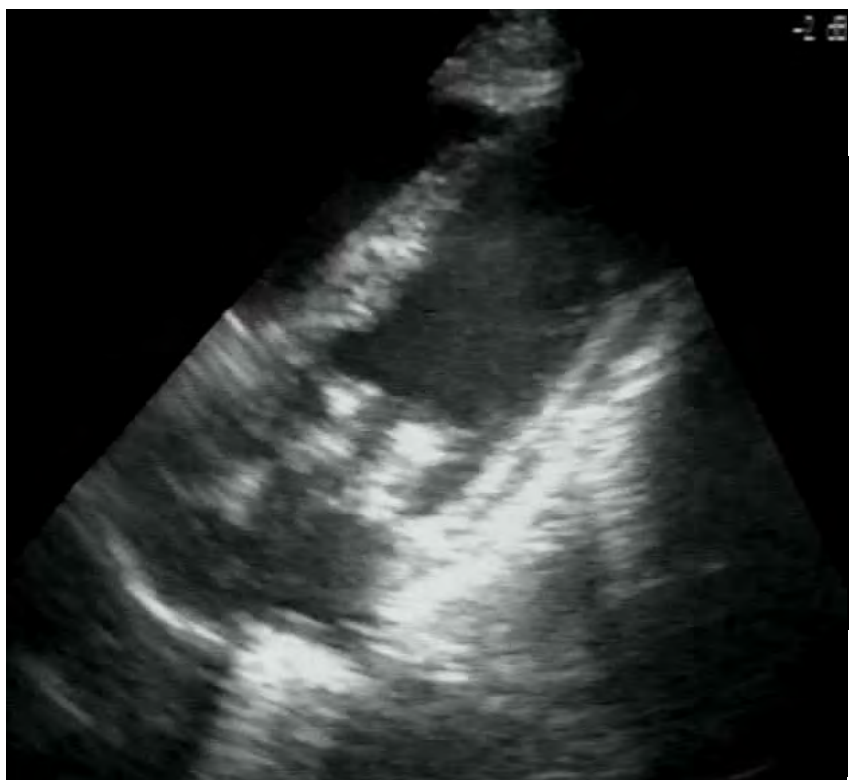

Video 2. Echographic imaging showing the valve in valve concept in mitral position in a sheep. (Boudjemline et al, Eur Heart J. 2005;26:2013-7.)

sibility of controlling reversibly the deployment of the valved stent as many times as needed before the final release, to allow implantation in appropriate position (Figure 1 and Videos 3 to 7).

Since then successful percutaneous valvein-valve implantations in humans have been especially reported for pulmonary and aortic valves $[12,13]$. The first human case of transcatheter valve-in-valve implantation in the tricuspid position was described by Van Garsse and colleagues [14]. Since then several anecdotal case reports and small case series using two different valves: the Melody ${ }^{\circledR}$ valve (Medtronic, Minneapolis, Minnesota, USA) and the Edwards SAPIEN $^{\mathrm{TM}}$ valve (Edwards Lifesciences, Irvine, California, USA) have been described [15-22]. These procedures were performed in a heterogeneous population, including children and adults with congenital heart disease, patients with prior infective endocarditis, and patients with a history of rheumatic or carcinoid heart disease.

The first multicentric series of percutaneous tricuspid VIV replacement using Melody valve in 15 patients with good results was published in 2011 (age range 8 to 64 years) [16]. The primary indication for the procedure was predominantly stenosis in 10 and regur- 


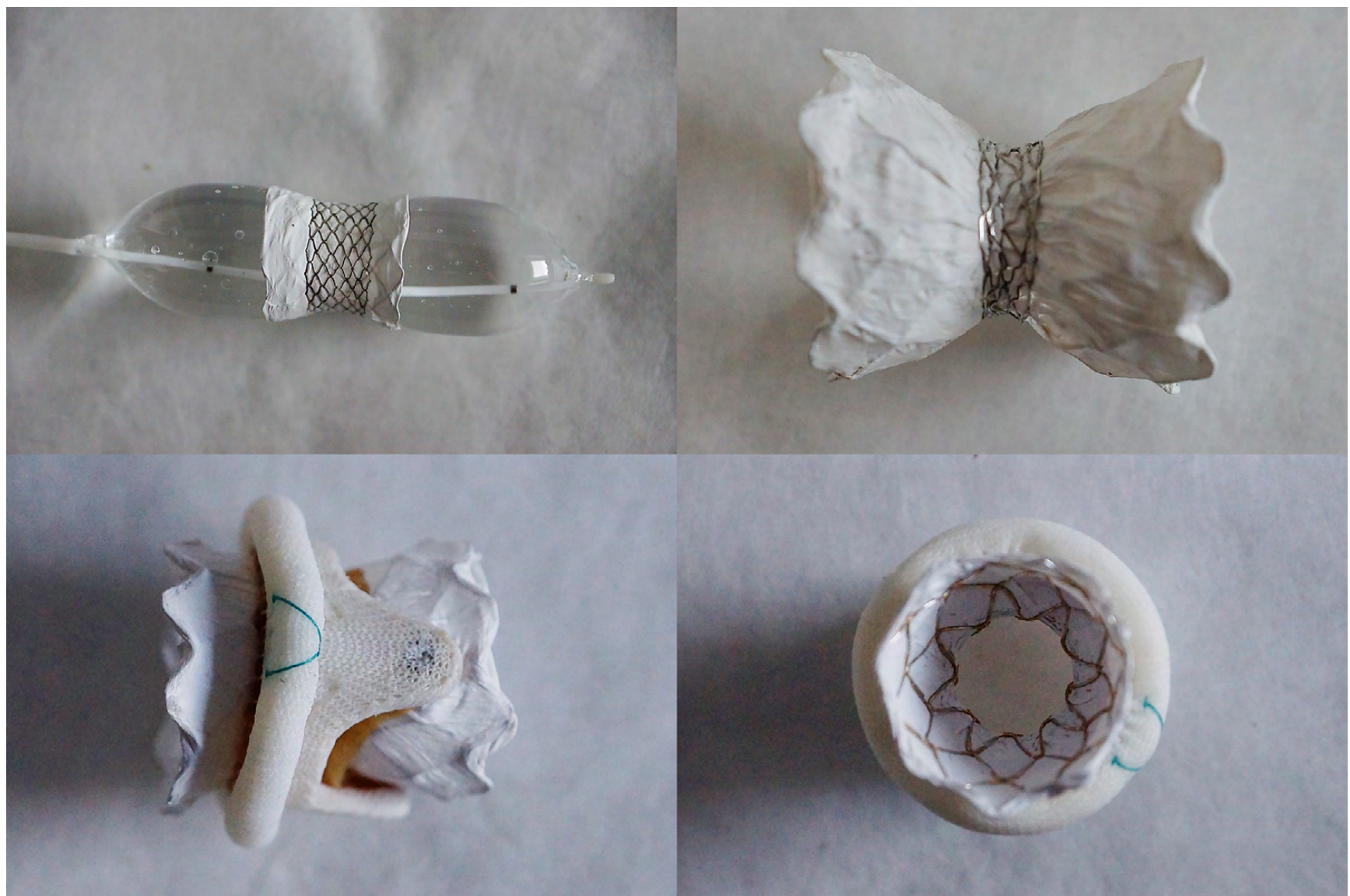

Figure 2. Implantation of a valved stent in large tricuspid annulus. Creation of a platform. The platform is created using the property of 2 different stents used simultaneously with one fitted within the second one: 1/ a bare metal stent with limited expansion (typically short EV3 LD mega) allows a restrictive region for subsequent valve insertion; 2/ a covered stent without limited expansion (typically long covered CP stent) allows anchoring to the large surgically inserted bioprosthesis. Top left. EV3LD mega is mounted on a long covered CP stent over a balloon. The balloon is being inflated. Top right. in vitro aspect after deflation and retrieval of the balloon catheter. The stent assembly has now the aspect of a Dumbbell stent creating a perfect platfrom for a valved stent. Below/left. front view of the stent assembly within a bioprosthetic surgical valve. The extremities of the stent assembly are holding on the frame of the bioprosthetic valve. Below/right. axial view of the stent assembly within a bioprosthetic surgical valve. 2 different diameters are shown. The middle part is smaller than the extremities. This middle part will hold the valved stent to be implanted.

gitation in 5 . The valve was successfully placed in all patients via the femoral vein in 11 and the internal jugular vein in 4 patients. Pre-dilation or low-pressure balloon sizing was performed in four patients before valve implantation while pre-stenting was not described. Post-implantation dilation using highpressure balloons was performed in seven patients. The median post-procedure tricuspid gradient was $2 \mathrm{~mm} \mathrm{Hg}$ and no patient had more than mild regurgitation. After a median follow-up of four months, 14 of 15 patients who underwent the Melody valve implantation are alive and well. Complications included one death in a patient with pre-procedural multi-organ failure, one with third-degree heart block requiring pacemaker implantation, and one case of endocarditis requiring valve removal 2 months after implantation.

Recently, a similar case series reporting percutaneous implantation of the Melody valve within failed mitral $(n=10)$ and tricuspid $(n=9)$ bioprosthetic valves was published [23]. Among tricuspid patients (mean age $42 \pm 24$ years), mean transvalvular gradient was $10 \pm 4.3 \mathrm{~mm} \mathrm{Hg}$ among and seven patients had moderate or worse tricuspid valve regurgitation. Imaging was performed with intracardiac echocardiography 


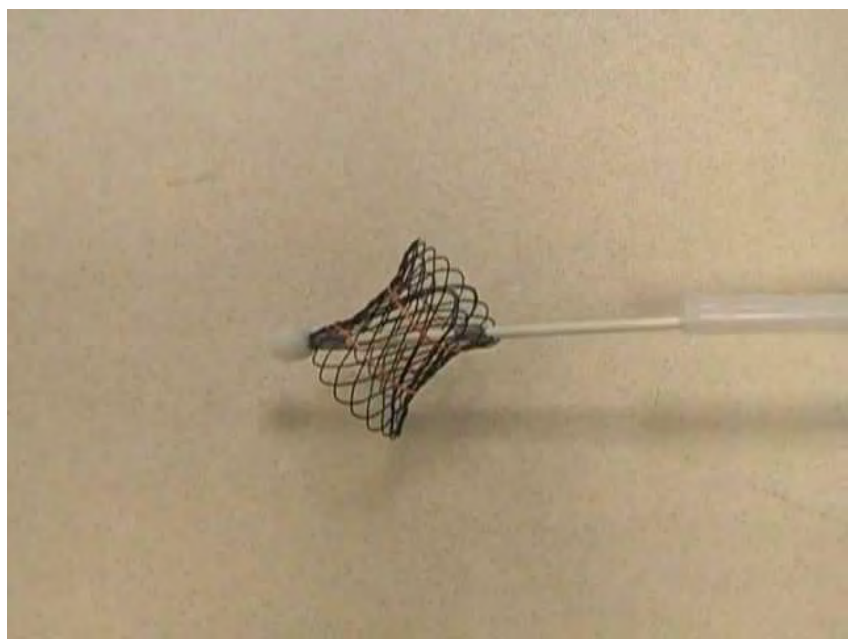

Video 3. In vitro Video showing a custom-made retrievable stent. (Zegdi et al, JACC. 2006;48:1365-8).

in seven patients and TEE in three patients. Balloon sizing of the prosthesis was performed in all patients, no prestenting was described. All patients underwent successful implantation of a $22-\mathrm{mm}$ Melody valve with satisfactory results. No periprocedural death, stent fracture or valve embolization was observed. During follow up, two patients had vascular complications (femoral artery pseudo aneurysm and femoral vein phlebitis) and one patient was operated for a Melody valve thrombosis due to heparin-induced thrombocytopenia.

Despite the promising results of the percutaneous tricuspid valve-in-valve implantation, a case series describing early failure of Melody and Sapien valves in the tricuspid position was recently published [24]. Authors describe four procedures in three patients where implantation of percutaneous valves within bioprosthetic tricuspid valves was performed with excellent immediate post procedural results. However, in all four cases evidence of rapid valve failure within 2 weeks following intervention in three of the four cases and later in the fourth case was described. Two patients required surgical explantation and subsequent examination of the prosthesis showed degeneration with thickening and contraction of the leaflets. Routine blood tests including immunological and inflammatory markers were normal without evidence of endocarditis. Authors suggested that individual factors and/or hemodynamic conditions

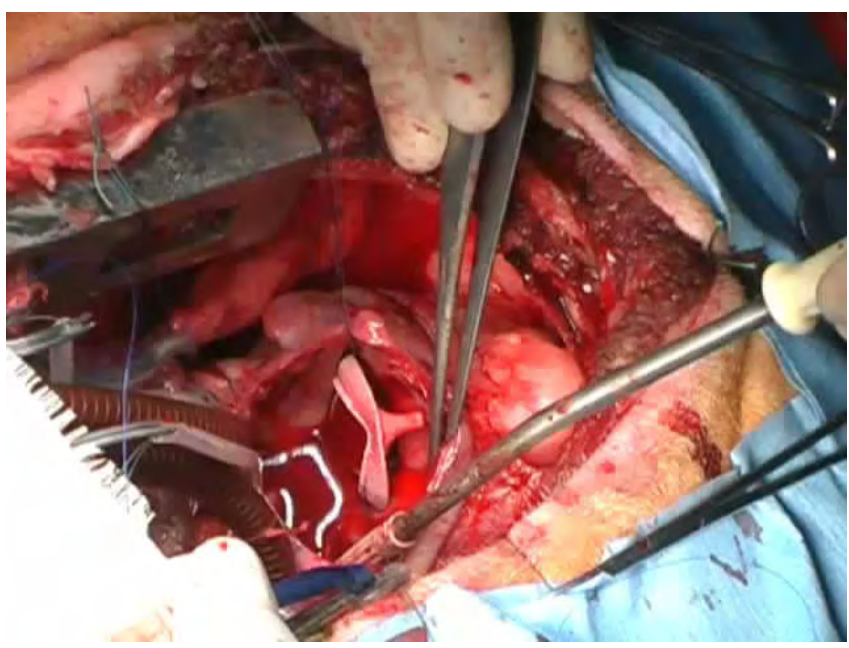

Video 4. Video showing the valve in valve concept in tricuspid position in a sheep. A regurgitant bioprosthetic valve is surgically placed (Zegdi et al, JACC. 2006;48:1365-8).

associated with dilated poorly contractile right atria leading to limited valve leaflet mobility may explain this rapid deterioration; however these observations remain partially unexplained. We observed similar findings in failing Fontan patients receiving a Melody in the Fontan circulation [25].

The primary indication for tricuspid valve-in-valve implantation remains a key point of this procedure. If the predominant lesion of the bioprosthetic valve is stenosis (with or without regurgitation), the procedure may be then performed using standard technique. The size of the original surgical valve is not important. The only burning question in that situation is to know if the stenosis could be opened enough to reduce the transvalvular gradient. Recently, a Spanish team reported the successful implantation of a $29-\mathrm{mm}$ Edwards-SAPIEN XT prosthesis within a 31-mm stenotic tricuspid bioprosthesis through a transfemoral approach [26]. The procedure was carried out without predilatation or balloon sizing of the bioprosthesis. Prestenting is rarely performed during tricuspid valve in valve implantation. This is in contrast with percutaneous pulmonary valve implantation where pre-stenting is most of the time necessary to create a stable landing zone and to prevent stent fracture in the right ventricular outflow tract. However, as the tricuspid valve is in general far away from right ventricular muscular bands as well as from the sternum, valved stent fracture is not a major issue in the 


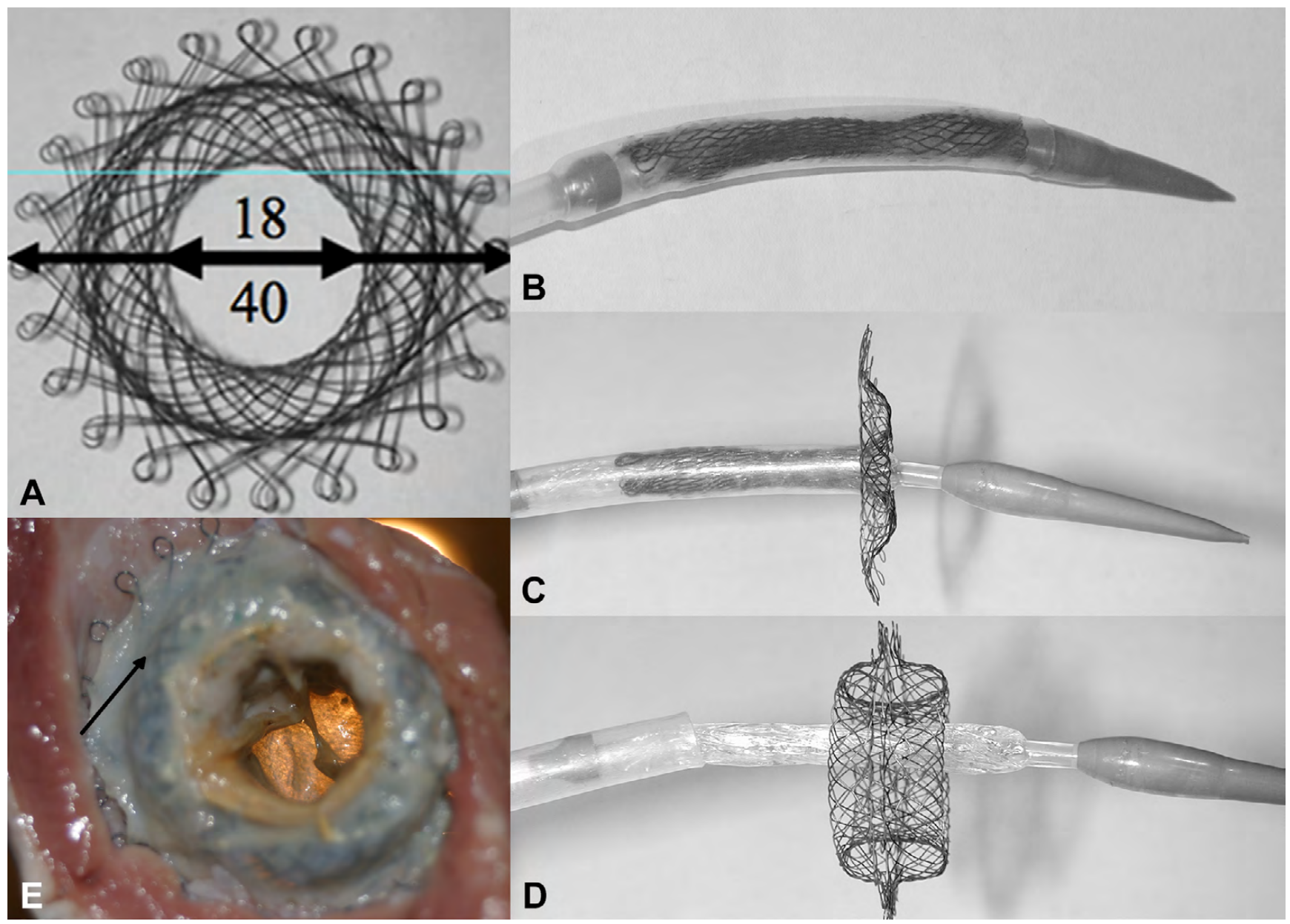

Figure 3. Self expanding valved stent for percutaneous tricuspid valve replacement (Boudjemline et al. réf 36). A. The device consists in a nitinol self-expandable stent formed of two disks (40-mm diameter) separated by a tubular part (15-mm length, 18-mm diameter) containing a bovine jugular vein valved. to guarantee the sealing of the device. B, C and D. Deployment of the device on bench testing. The device is loaded into a « homemade » delivery system (B), the right ventricular disk is deployed in the by pulling on the external sheath while maintaining the dilator in position; this disk is subsequently applied to the tricuspid annulus by pulling on the external sheath and dilator (C), then the atrial disk is delivered similarly, making the two disks sandwiching the tricuspid annulus (D). E. Macroscopic view of the valved stent from the right ventricular side. ${ }^{*}$ bovine jugular vein segment sutured into the tubular part of the device; avoid paravalvular leakage, a polytetrafluoroethylene membrane is sutured outside the ventricular disk (black arrow).

tricuspid position. However it is important to remember that widest excursion of annular plane occurs at the tricuspid location. The structural framework present in most of the tricuspid bioprosthetic valves may offer protection from compressive and rotational forces and thus from stent fractures.

If the tricuspid valve failure leads exclusively to regurgitation, then the dimensions of the valve (especially the inner diameter) must be precisely known and evaluated by the operator during the procedure using a balloon sizing. Others and we have reported specific techniques to make these patients amenable to transcatheter valve insertion. Briefly, presenting is required in that situation. The first step is to create a restrictive landing zone to allow for a safe deployment of a Melody valve. The platform is created using the property of 2 different stents used simultaneously with one fitted within the second one: 1.) A bare metal stent with limited expansion (typically short EV3 LD mega) allows a restrictive region for subsequent valve insertion; 2.) A covered stent without limited expansion (typically long covered CP stent) allows an- 


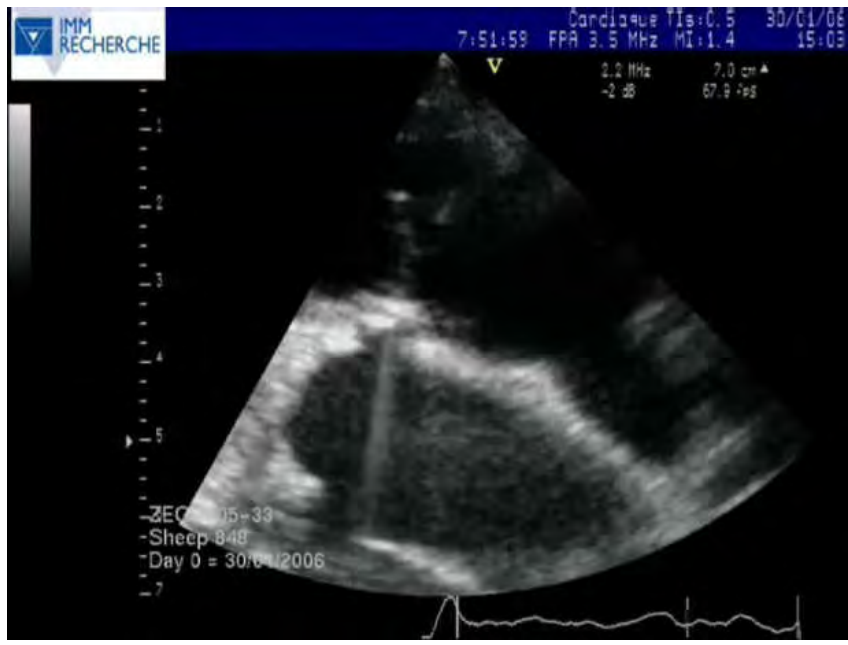

Video 5. Echographic Video showing regurgitation of the implanted bioprosthetic surgical valve (Zegdi et al, JACC. 2006;48:1365-8)

choring to the large surgically inserted bioprosthesis (Figure 2). Type and diameter of balloons used to deliver the stents largely depends on the inner diameter of the surgical valve. Following the creation of the landing zone, transcatheter valves insertion could be performed using conventional technique. Using this technique, we treated patients with regurgitant surgical valve up to 33-mm in diameter. In our experience, the creation of free tricuspid regurgitation following prestenting is well tolerated and no rush is needed to implant the valve.

Excluding the transatrial hybrid procedures with direct right atrial puncture [27], completely percutaneous tricuspid valve-in-valve implantations were performed using either a femoral or an internal jugular venous approach.

In cases where the tricuspid valve prosthesis is directed toward the superior vena cava, the transjugular approach should be preferred to obtain a better angle when positioning the valve, especially with the Edwards SAPIEN valve that is a larger and more rigid device. Nevertheless, despite these considerations, the decision about the approach has to be taken separately for each patient regarding patient's valve anatomy.

Rapid pacing is generally performed during Edwards SAPIEN implantation to allow accurate positioning of this relatively short valve. It is usually not

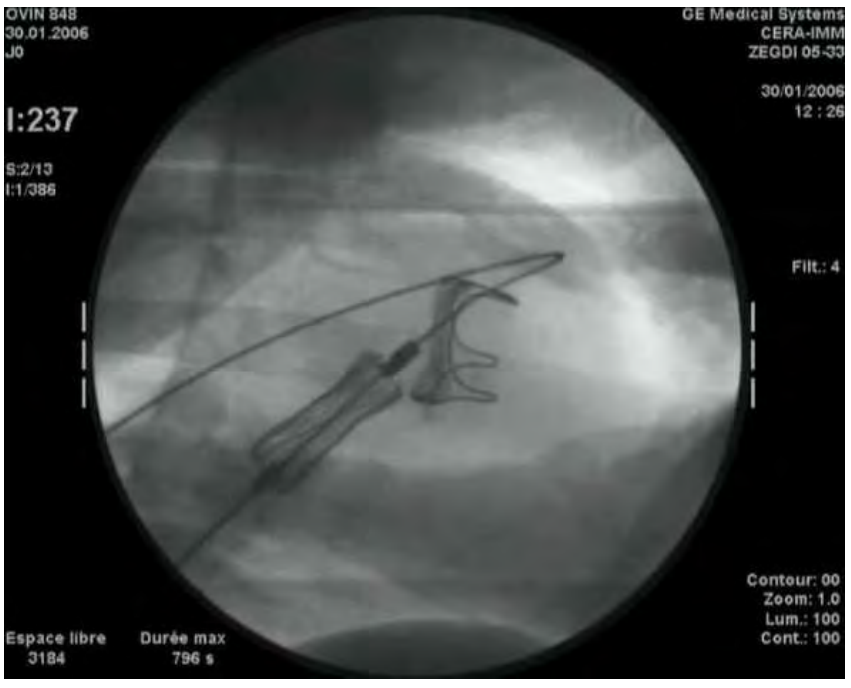

Video 6. Angiogram showing the implantation of the retrievable valve stent. The stent is slowly opened inside the bioprosthesis than closed and repositioned and finally released and left in position. (Zegdi et al, JACC. 2006;48:1365-8).

required with the longer Melody valve. In our experience, rapid pacing is not necessary and femoral veins provide excellent access to the tricuspid. During positioning on the valved stent, the assembly can easily be aligned (horizontalized) to the tricuspid annulus by maintaining forward pressure on the stiff wire thus mimicking jugular pathway.

The Edwards SAPIEN ${ }^{\circledR}$ valve has the advantage of being available in larger sizes with relatively shorter stent lengths (the $26-\mathrm{mm}$ valve measures $16-\mathrm{mm}$ in length) when compared with the MELODY ${ }^{\circledR}$ Valve (the stent measures $23 \mathrm{~mm}$ in length when dilated to 22 $\mathrm{mm})$. Moreover, its shorter stent may not protrude significantly into the adjacent cardiac chambers. On the other hand, correct positioning of this shorter valve may be more difficult, although rapid pacing may be used to allow safer implantation, and manipulation of the Melody delivery system is easier in complex anatomies with important angulation of the tricuspid annulus in relation to the superior vena cava and inferior vena cava.

Despite experience is accumulating worldwide with these two devices, there is currently lack of data to conclude that one of the devices is superior to the other in this off-label use. 


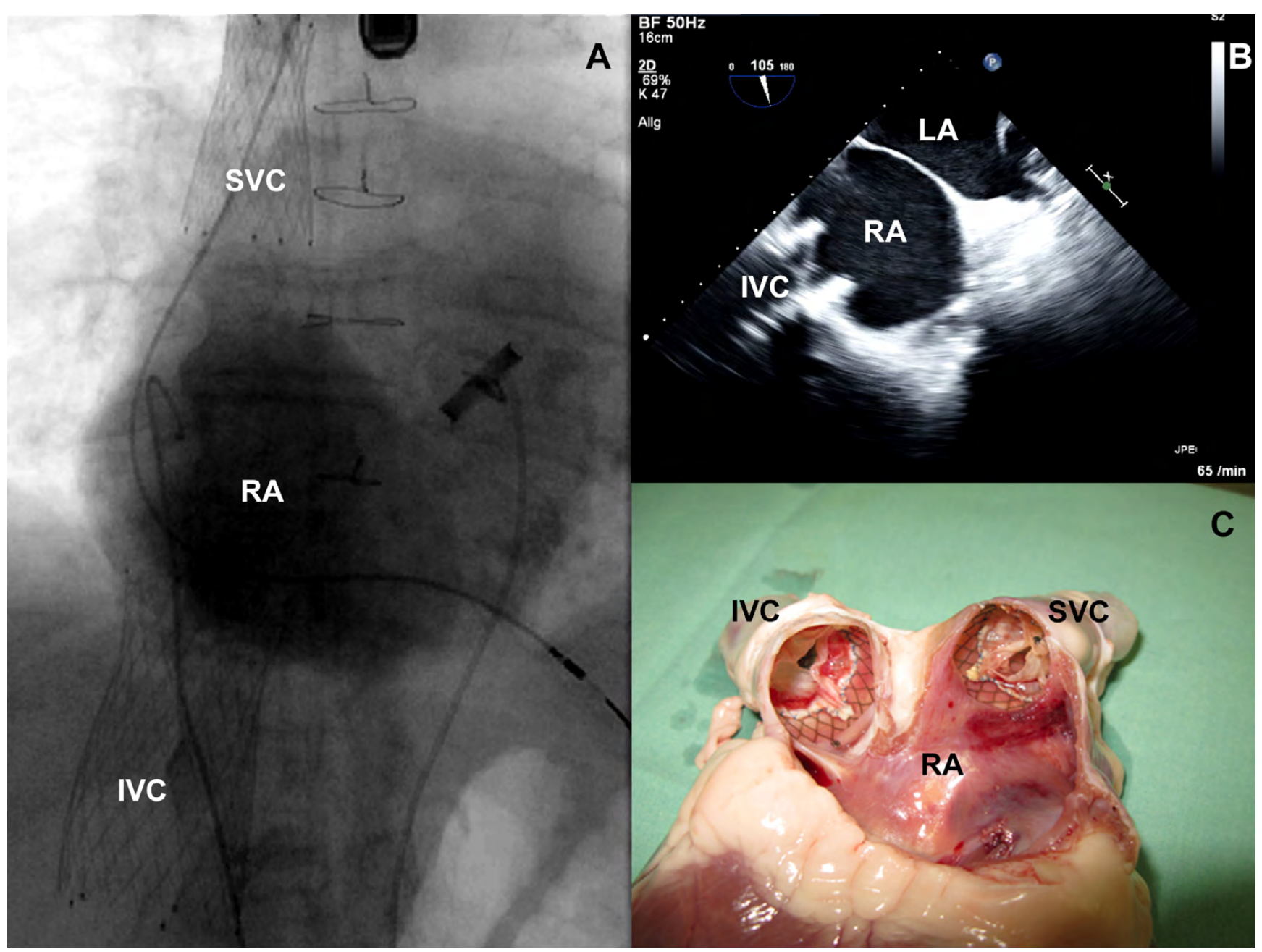

Figure 4. Transcatheter bicaval valve implantation. A. Fluoroscopy - Right atrial angiography: The inferior vena cava (IVC) valve is designed with the upper segment protruding into the right atrium (RA), the superior vena cava (SVC) device is funnel shaped to facilitate anchoring at the cavoatrial junction. Contrast is retained at the level of the valved stents. RA: right atrium; SVC: superior vena cava; IVC: inferior vena cava. B. Transoesophageal echocardiography: long-axis view of the IVC device after deployment. C. Post mortem specimen macroscopic view: the valved stents are securely anchored with the stent struts covered by fibrous tissue, fixing the devices.

\section{Valve-in-Ring Therapy}

Based on the principle of valve in valve, a completely rigid annuloplasty ring may also offer adequate anchoring support and landing zone. The first experiments were performed for the mitral valve. In an animal study, Kempfert et al. [28] showed that an off-pump transatrial transcatheter valve in ring implantation using 23-mm Edwards Sapien ${ }^{\circledR}$ valve in a 26-mm Physio ${ }^{\circledR}$ mitral ring was feasible with good heamodynamic results. One main concern was the oval shape of the Physio ${ }^{\circledR}$ ring versus the circular shape of the Sapien ${ }^{\circledR}$ valve. However, in bench testing, authors demonstrated the adaptability of the Physio ${ }^{\circledR}$ ring into a circular form at balloon insufflations. Subsequently, several papers reported mitral valve-in-ring implantation through a left ventricular trans apical approach in compassionate-use procedures for patients with high surgical risk [29, 30]. Indeed, the first in man implantation of a transcatheter valve in a mitral annuloplasty ring was performed in a 72-year-old man with ischemic heart failure (ejection fraction 35\%) and severe mitral regurgitation. A 26-mm Sapien-Edwards aortic valve was successfully 
implanted during rapid right ventricular pacing within the 28-mm Physio ${ }^{\circledR}$ mitral annuloplasty ring with equal proportions within the left ventricle and the left atrium, using fluoroscopy and transesophageal echocardiography guidance.

The first transcatheter tricuspid valve-in-ring implantation was described by Mazzitelli et al. [31]. They reported the case a of a combined off-pump ante grade trans-atrial implantation of a 26-mm Sapien ${ }^{\circledR}$ valve within mitral and tricuspid annuloplasty rings (Physio ${ }^{\circledR} 28-\mathrm{mm}$ and $26-\mathrm{mm}$ respectively) through an anterolateral minithoracotomy in a 61-year-old woman. The direct trans-atrial approach was considered to be ideal to treat both valves at the same time. The patient was extubated after 24 hours and discharged on the ninth postoperative day with satisfactory valvular function (minor paravalvular tricuspid regurgitation). Shuto et al. [32, 33] described the first completely percutaneous valve-in-ring implantation using the Melody ${ }^{\circledR}$ device in a mitral ring. Via standard vascular access and transseptal techniques, they successfully deployed the Melody ${ }^{\circledR}$ valve into the mitral position from the venous circulation in five sheep, without complication. Although there was a conformational change noted in the implanted Melody ${ }^{\circledR}$ valves from "round" to "oval", there was no perivalvular leakage and only trivial to mild central regurgitation was observed. These results were confirmed in another animal study using 4 distinct types of annuloplasty ring.

The complete percutaneous approach was recently used to perform a tricuspid VIR implantation in a 64-year-old female who underwent placement of a mitral valve homograft with a \#34 Physio ${ }^{\circledR}$ ring (Edwards Lifesciences, Irvine (A, USA) in the tricuspid position in whom echocardiography revealed severe tricuspid stenosis with a mean gradient of $16 \mathrm{~mm} \mathrm{Hg}$ with mild tricuspid regurgitation [34]. A transcatheter $26 \mathrm{~mm}$ Edwards SAPIEN ${ }^{\circledR}$ valve was placed in the tricuspid position through a femoral vein approach, resulting in near normalisation of tricuspid valve gradient. Prosthesis size was estimated by computed tomography, intracardiac echocardiography, and finally by balloon sizing during the procedure. Furthermore, a pre-stenting technique was used to ensure appropriate coverage of the valvular orifice and make valve positioning easier although the presence of a complete rigid Physio ${ }^{\circledR}$ ring may theoretically facilitate prosthesis apposition, and reduce the risk of device embolization or paravalvular leak. A similar case was recently reported using the same approach and the same transcatheter $26 \mathrm{~mm}$ Edwards SAPIEN ${ }^{\circledR}$ prosthesis [35].

For transcatheter VIR implantations, the dimensions of the tricuspid valve annulus are better approximated by the commercially available SAPI$\mathrm{EN}^{\circledR}$ valves (up to $26 \mathrm{~mm}$ in diameter) than the Melody valves (maximum expandable diameter $22 \mathrm{~mm}$ ). However, because of the conception of the Edwards valve (made of manufactured three equal pericardial leaflets), the device should be open as close as possible to its nominal diameter and as round as possible to allow enough flow and closing volume and thus avoid functional stenosis or leak. Melody valve is more versatile and can be open to various diameters and configuration without impinging the valvar function. However expansion of Melody valves to diameters larger or equal to $25-\mathrm{mm}$ has been associated in with valvular incompetence and device embolization when implanted in mitral rings [33]. Nevertheless, the valve-in-ring approach for atrioventricular valves may extend the functional life of the surgical substrates in a manner analogous to Melody ${ }^{\circledR}$ and Sapien ${ }^{\circledR}$ valve treatment for dysfunctional surgical conduits in the pulmonary position.

\section{Percutaneous Treatment of Native Tricuspid Valves}

In native tricuspid valves, implanting a trancatheter prosthesis remains challenging because of the absence of a stiff region to anchor the valve, and the lack of fluoroscopic markers and the difficulties to precisely assess annulus measurements (due to the absence of tricuspid surgical markers such as ring or bioprosthesis). However, strategies have been developed to perform not only percutaneous tricuspid valve replacement whether in orthotopic or heterotopic position, but also a conservative transcatheter tricuspid valvuloplasty.

\section{Transcatheter Orthotopic TV Replacement}

In 2005, Boudjemline et al. [36] designed a new device intended to be implanted percutaneously in native tricuspid valves and published the first study 


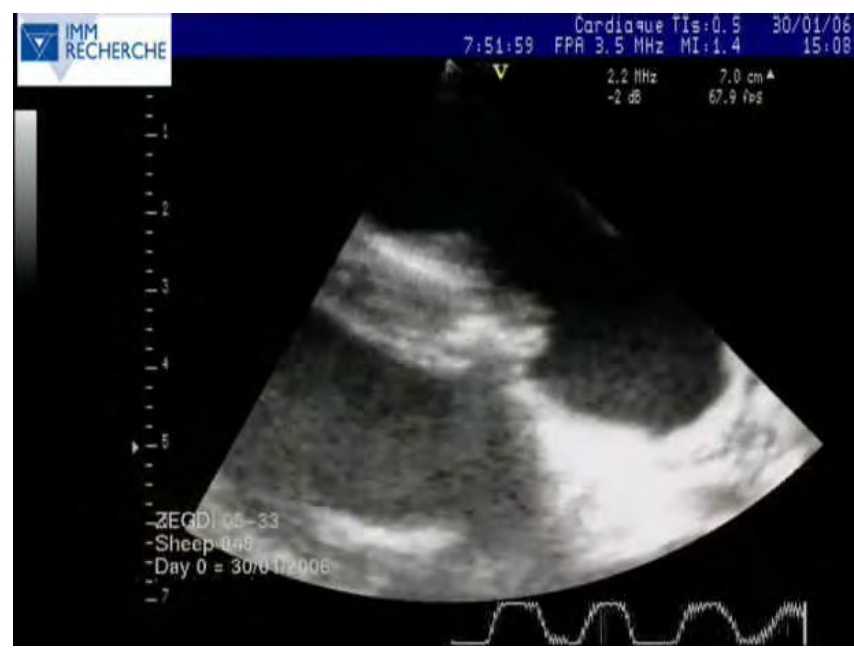

Video 7. Echographic Video after transcatheter valve implant showing correction of the regurgitation of the implanted bioprosthetic surgical valve (Zegdi et al, JACC. 2006;48:1365-8). with percutaneous tricuspid valve implantation in 8 healthy ewes. This prosthesis consisted in a nitinol self-expandable stent formed of two disks (40$\mathrm{mm}$ diameter) separated by a tubular part (15-mm length, 18-mm diameter) containing a bovine jugular vein valved segment. A polytetrafluoroethylene membrane was sutured outside of the ventricular disk to guarantee the sealing of the device. The diameter of the two disks was chosen to be slightly larger than the diameter of the tricuspid annulus to allow for anchoring (Figure 3 and Videos 8 to 11). Mechanical fixation was ensured by trapping the annulus between the two disks. In one animal, the device was trapped in tricuspid chordae, leading to its incomplete opening. A significant paravalvular leak was observed in one animal, due to a torn the PTFE membrane beside a weld fracture.

Other authors described a similar valved stent; a porcine pericardial valve mounted on a double-edge nitinol stent with satisfactory results in a chronic sheep model despite 2 device embolization upon 10 procedures [37].

Moreover, lino et al. describe another device, a bovine pericardial valve mounted on a self-expandable nitinol stent with a super-absorbent polymer placed

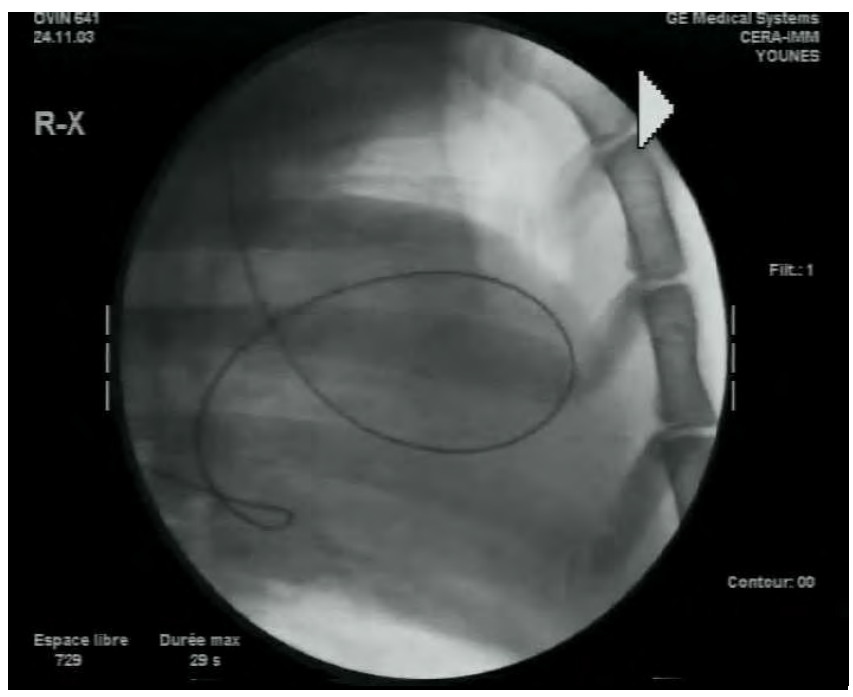

Video 8. Video showing the delivery of a valved stent in tricuspid native valve. The delivery system is advanced over a wire in the right ventricle. The RV disk is slowly opened in the apex of the RV and pullback in the tricuspid annulus. The device is then completely opened and delivered (Boudjemline, JACC. 2005;46:360-5).

beneath the right atrial element for minimizing paravalvular leak. This device was successfully implanted in pigs through a mini-thoracotomy using trans-ventricular approach with a reduction of paravalvular leakage [38].

Although these papers opened perspectives into transcatheter orthotopic native tricuspid valve replacement, no further experimental developments or human implantation were published with these devices.

Recently, Kefer et al. [39] published the first human transcatheter implantation in a "native" tricuspid valve using a 26-mm Sapien ${ }^{\circledR}$ valve after failed multiple surgical repairs in a 47-year-old female. Tricuspid annulus size was assessed by magnetic resonance imaging, three-dimensional transesophageal echocardiography and especially low-pressure balloon sizing during the procedure. Prestenting was achieved by covered stent to create a rigid landing zone and to avoid paravalvular leak. As it is the case for VIR implantations, the dimensions of the tricuspid valve annulus were better approximated by the SAPIEN ${ }^{\circledR}$ valves than the Melody valves (maximum expandable diameter $22 \mathrm{~mm}$ ). However, after first valve implantation, severe paravalvular regurgitation was observed, related to a more apical position of the Sapien ${ }^{\circledR}$ valve. 


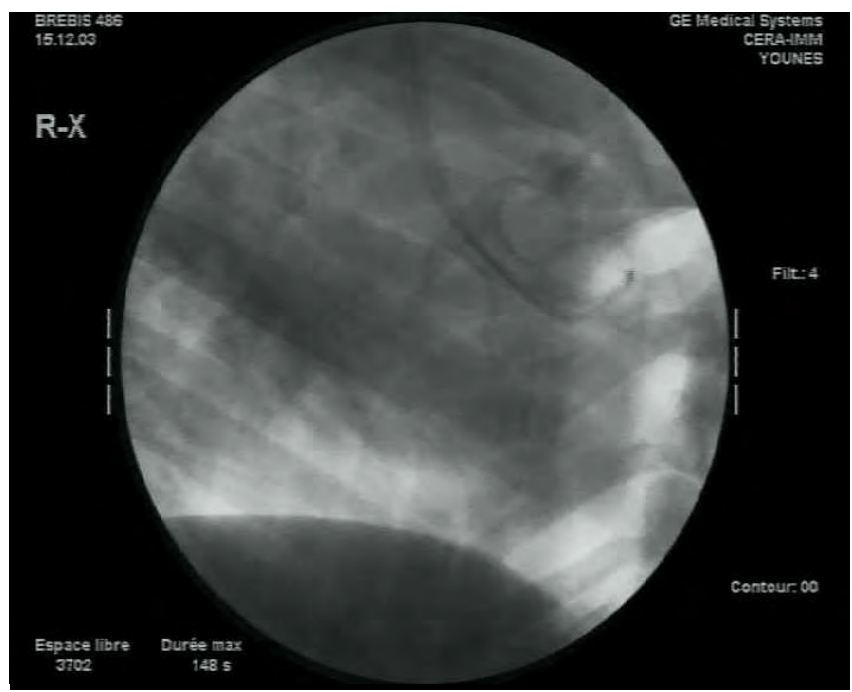

Video 9. Angiogram after release showing the competence of the newly implanted tricuspid valve. (Boudjemline, JACC. 2005;46:360-5).

A second Sapien ${ }^{\circledR}$ valve $26 \mathrm{~mm}$ was then implanted just proximal to the first one solving the tricuspid leak. This is likely due to that Sapien ${ }^{\circledR}$ valve has a covered length of only $10 \mathrm{~mm}$, significantly shorter than the Melody prosthesis (up to $23 \mathrm{~mm}$ ).

These issues may be resolved in the future with the development of specific devices with larger diameters and longer covered lengths, more appropriate for transcatheter valve implantation in the tricuspid position.

\section{Heterotopic TV Replacement or Caval Valve Implantation (CAVI)}

Lauten et al. [40, 41] evaluated in an animal study a percutaneous approach to treat native TV failure using heterotopic valve implantation in the central venous position. Using a right internal jugular vein approach authors implanted two self-expanding nitinol stents containing a porcine pulmonary valve in the superior and inferior caval veins of 13 sheep presenting severe tricuspid regurgitation. All but one valve was correctly deployed as intended (one device embolization in the right atrium) leading to a significant decrease of central venous pressure and cardiac output. This interesting concept with lack of intracardiac foreign material preventing venous flow rever-

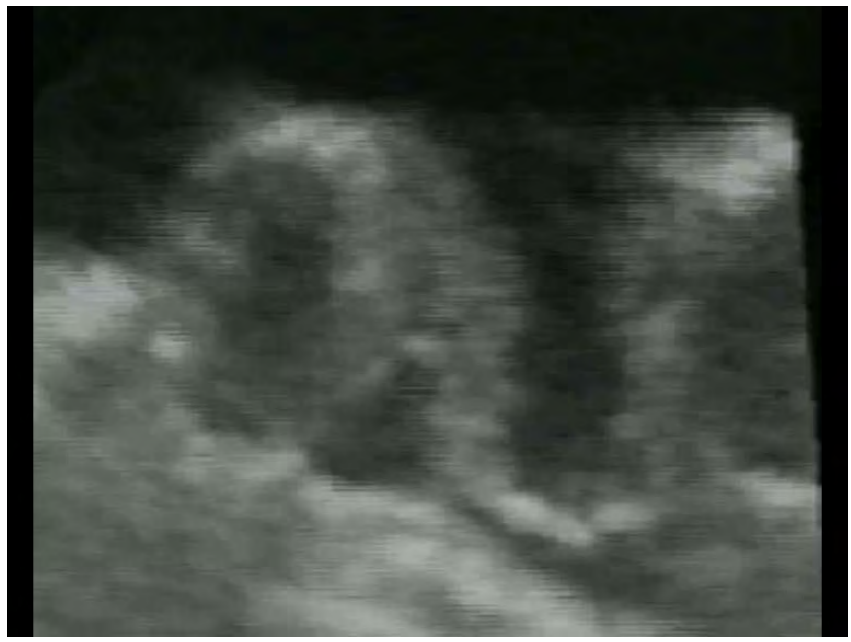

Video 10. Echographic Video in long axis view after transcatheter valve implant showing good function of the leaflets. (Boudjemline, JACC. 2005;46:360-5).

sals and possibly hepatic complications fails to keep the right atrial and ventricular dilatation under check and may lead to potential deleterious hemodynamic and rhythmic effects.

Subsequently, the first-in-man application of this concept was performed as a compassionate treatment in a 79-year-old female patient with severe functional tricuspid regurgitation. Through the femoral vein, a custom-made self-expanding valved stent was implanted into the inferior vena cava, anchored at the cavoatrial junction. After deployment, excellent valve function was observed without paravalvular leakage resulting in a marked reduction in caval pressure. The patient experienced improved physical capacity and a partial reduction of ascites. The patient died 3 months after the procedure from intracranial haemorrhage (Figure 4). Autopsy confirmed an unchanged position and excellent function of the valve in the IVC without evidence of degeneration, thrombus formation, or other causes of dysfunction $[42,43]$. The same team published recently the case of a similar case of an 83 years-old female who underwent implantation of 2 custom-made self-expanding valved stents into the superior and inferior vena cava without complication. The procedure (CAVI) resulted in an immediate and sustained hemodynamic improvement. Moreover, the patient showed a substantial clinical 


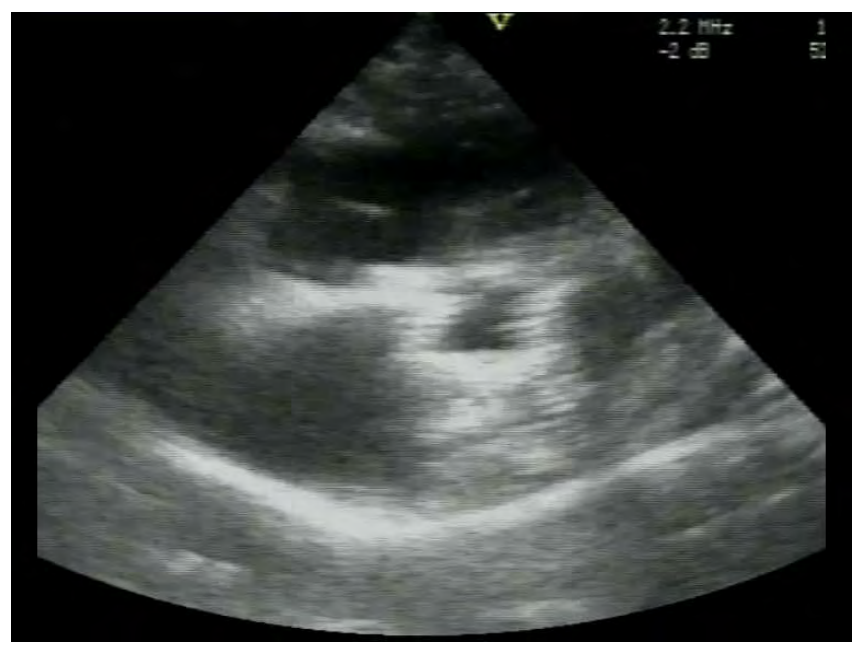

Video 11. Echographic Video in transverse axis view after transcatheter valve implant showing the position of the valve stent in regards with the original tricuspid annulus. (Boudjemline, JACC. 2005;46:360-5).

improvement of heart failure symptoms, normalization of liver function, and improvement of physical capacity after 12 months of follow-up [44]. To avoid right heart failure by increased preload, it seems that preserved right ventricular function is mandatory for the success of this procedure. Furthermore, because these valves are implanted in the low-pressure system, lifelong anticoagulation is required.

Laule et al. [45] reported a case series of three patients who had percutaneous caval valve implantation (CAVI) for severe tricuspid regurgitation (Videos 12 and 13). Procedures were performed using Edwards Sapien XT $(29 \mathrm{~mm})$ valved stent following superior and inferior vena cava prestenting. No complication occurred. After 1 month, valve function remained excellent without regurgitation or leakage and all patients improved by at least 1 NYHA class. In patients with enlarged inferior vena cava, a mini-invasive surgical caval banding can be performed to allow a safe valved stent implantation in appropriate landing zone [46].

Despite encouraging first results, further studies are warranted to evaluate the benefit of the heterotopic transcatheter tricuspid valve implantation procedure during long-term follow-up in larger cohorts. Furthermore, as this concept is targeted for

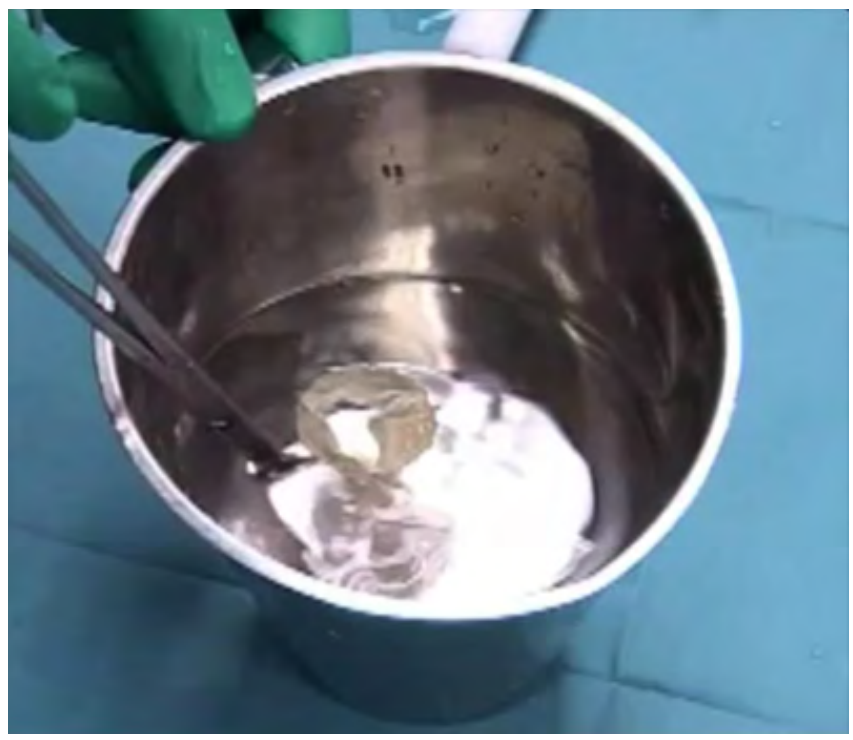

Video 12. Video showing preparation, implantation and angiogram of two self-expandable valved stents in a CAVI procedure. (Lauten, Circ Cardiovasc Interv. 2014;7:268-72).

high-risk patients in end-stage heart disease, the costs involved for this type of procedure should be taken into account and carefully weighed against the clinical benefit.

\section{Transcatheter Tricuspid Valvuloplasty}

Percutaneous procedures may be an attractive alternative to surgery for patients who are high-risk surgical candidates. In patients with native failed tricuspid valve, some of the concepts that have been developed for the percutaneous treatment of mitral regurgitation may be adapted to percutaneous repair of the tricuspid valve (percutaneous annuloplasty, edge-to-edge repair) $[47,48]$. The Millipede system (Millipede, LLC, Ann Arbor, Michigan, USA) consists in placing a new tricuspid annular ring with a unique attachment system through a minimally invasive approach - surgical or percutaneous. This repositionable and retrievable device may restore the native tricuspid annular shape and diameter and thus treat functional tricuspid regurgitation. It is currently under preclinical development. Furthermore, the use of the Mitralign Percutaneous Annuloplasty System (Mitralign Inc., Boston, Massachusetts, USA) or the QuantumCor System (QuantumCor, Inc., Bothell, Washington, USA) may in a near 
future be extended to tricuspid valve as well.

\section{Challenges}

The large diameter, dynamic and highly variable nature of tricuspid annulus with the relatively poor fibro skeletal support is an important limitation $[49,50]$. With limited annular contractile property in contrast to the mitral annulus, it is important to assess load independent indices of right ventricular contractility especially of the sub-annular fibers. The minimum required $\mathrm{RV}$ contractility to ensure a good closing volume, the minimum required cardiac output and possibly RA contractility to ensure adequate opening of the valve without clogging and maintain long-term durability is yet to be defined. The need for a low profile self-expanding valve that may reach an outer diameter of $70 \mathrm{~mm}$ as known in patients with clinically significant and functional tricuspid regurgitation is another challenge. An ideal length of the covered stent is also important to prevent inadvertent encroachment of the tricuspid valve apparatus and its neighborhood including right ventricular outflow tract. Other challenges include creating a stable landing zone in native valves, preventing stent fracture and paravalvular leaks.

The exponential increase in right and left sided valvular interventions may possibly unfold the natural and unnatural history of primary and secondary tricuspid annular dilation and help our understanding for the creation of a stable, self expanding percutaneous valve with minimal paravalvar leak. Demonstrating a safe and economically viable strategy with good long-term outcomes may also be required as the devices evolve.

\section{Conclusion}

Over the past decade, there has been a paradigm shift in the interventional armamentarium for the

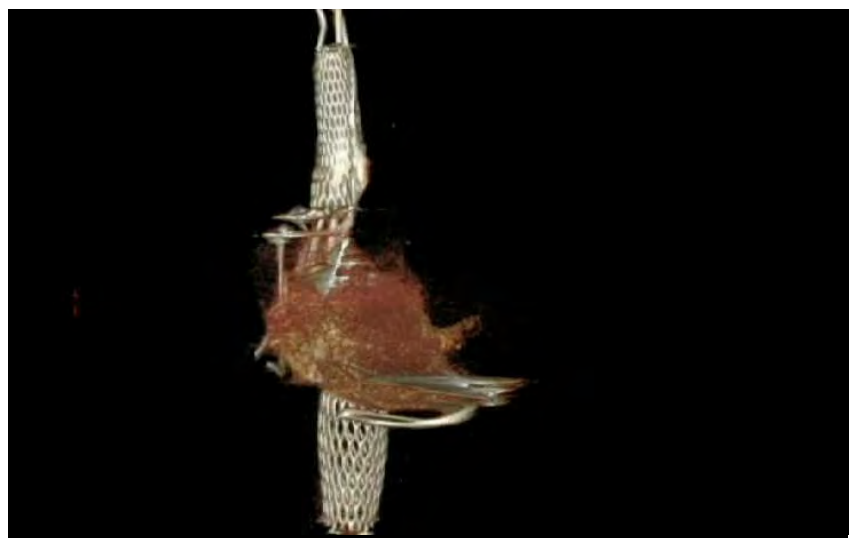

Video 13. $3 \mathrm{D} C \mathrm{CT}$ performed in a patient following a CAVI procedure. (Lauten, Circ Cardiovasc Interv. 2014;7:268-72).

management of valvular disease with the introduction of newer, safer and low profile percutaneous valves. While the indications for percutaneous valve implantations at the aortic and pulmonary position are expanding, there has been very limited growth on the front of percutaneous treatment of tricuspid valve diseases. In selected patients with high surgical risk, initial results of percutaneous tricuspid valve treatment is encouraging for various valvular substrates such as native valves, annuloplasty rings and bioprosthesis. Evolving strategies with newer percutaneous valves for eligible patients with tricuspid valve failure is likely to improve outcomes if done in a timely manner before the onset of irreversible right ventricular pump failure and may even reduce the need for a right ventricular assist device.

\section{Conflict of Interest}

Younes Boudjemline is a Proctor for Medtronic Inc.

\section{Comment on this Article or Ask a Question}

\section{References}

1. Brown ML, Dearani JA, Danielson GK, Cetta F, Connolly HM, Warnes CA, et al. The outcomes of operations for 539 patients with Ebstein anomaly. J Thorac Cardiovasc Surg. 2008;135:1120-1136. DOI: 10.1016/j. jtcvs.2008.02.034

2. Carrier $M$, Hebert $Y$, Pellerin $M$, Bouchard $D$, Perrault LP, Cartier R, et al. Tricuspid valve replacement: An analysis of 25 years of experience at a single center. Ann Thorac Surg. 2003;75:47-50. PMID: 12537191

3. Vahanian A, Alfieri $O$, Andreotti F, Antunes MJ, Baron-Esquivias G, Baumgartner $\mathrm{H}$, et al. Guidelines on the management of valvular heart disease (version 2012). Eur Heart J. 2012;33:2451-2496. DOI: 10.1093/ eurheartj/ehs109

4. Filsoufi F, Anyanwu AC, Salzberg SP, Frankel T, Cohn LH, Adams DH. Long-term outcomes of tricuspid valve replacement in the current era. Ann Thorac Surg. 2005;80:845-850. PMID: 16122441

5. Webb JG. Percutaneous aortic valve replacement will be a common treatment 
for aortic valve disease. JACC Cardiovasc Interv. 2008;1:122-126. DOI: 10.1016/j. jcin.2007.11.010

6. Zajarias A, Cribier AG. Outcomes and safety of percutaneous aortic valve replacement. J Am Coll Cardiol. 2009;53:1829-1836. DOI: 10.1016/j.jacc.2008.11.059

7. Bonhoeffer $P$, Boudjemline $Y$, Saliba Z, Merckx J, Aggoun $Y$, Bonnet $D$, et al. Percutaneous replacement of pulmonary valve in a right-ventricle to pulmonary-artery prosthetic conduit with valve dysfunction. Lancet. 2000;356:1403-1405. PMID: 11052583

8. McElhinney DB, Hellenbrand WE, Zahn EM, Jones TK, Cheatham JP, Lock JE, et al. Shortand medium-term outcomes after transcatheter pulmonary valve placement in the expanded multicenter US melody valve trial. Circulation. 2010;122:507-516. DOI: 10.1161/CIRCULATIONAHA.109.921692

9. Webb JG, Wood DA, Ye J, Gurvitch R, Gurvitch $R$, Masson JB, Rodés-Cabau J, et al. Transcatheter valve-in-valve implantation for failed bioprosthetic heart valves. Circulation. 2010;121:1848-1857. DOI: 10.1161/ CIRCULATIONAHA.109.924613

10. Boudjemline Y, Pineau E, Borenstein N, Behr L, Bonhoeffer P. New insights in minimally invasive valve replacement: description of a cooperative approach for the off-pump replacement of mitral valves. Eur Heart J. 2005;26:2013-2017. PMID: 15872031

11. Zegdi R, Khabbaz Z, Borenstein N, Fabiani JN. A repositionable valved stent for endovascular treatment of deteriorated bioprostheses. J Am Coll Cardiol. 2006;48:1365-1368. PMID: 17010796

12. Gillespi MJ, Rome JJ, Levi DS, Williams RJ, Rhodes JF, Cheatham JP, et al. Melody valve implant within failed bioprosthetic valves in the pulmonary position a multicenter experience. Circ Cardiovasc Interv. 2012;5:862-870. DOI: 10.1161/CIRCINTERVENTIONS.112.972216

13. Walther T, Falk V, Dewey T, Kempfert J, Emrich F, Pfannmüller B, et al. Valve-in-avalve concept for transcatheter minimally invasive repeat xenograft implantation. J Am Coll Cardiol. 2007;50:56-60. PMID: 17601546

14. Van Garsse LA, Ter Bekke RM, van Ommen VG. Percutaneous transcatheter valve-in-valve implantation in stenosed tricuspid valve bioprosthesis. Circulation. 2011;123:e219-221. DOI: 10.1161/CIRCULATIONAHA.110.972836

15. Riede FT, Dahnert I. Implantation of a Melody $(R)$ valve in triscuspid position. Catheter Cardiovasc Interv. 2012;80:474-476. DOI: $10.1002 / \mathrm{ccd} .23404$

16. Roberts PA, Boudjemline Y, Cheatham JP,
Eicken A, Ewert P, McElhinney DB, et al. Percutaneous tricuspid valve replacement in congenital and acquired heart disease. J Am Coll Cardiol. 2011;58:117-122. DOI: 10.1016/j.jacc.2011.01.044

17. Gewillig M, Dubois C. Percutaneous rerevalvulation of the tricuspid valve. Catheter Cardiovasc Interv. 2011;77:692-695. DOI: $10.1002 / \mathrm{ccd} .22814$

18. Eicken A, Fratz $S$, Hager A, Vogt $M$, Balling G, Hess J. Transcutaneous Melody valve implantation in "tricuspid position" after a Fontan Björk (RA-RV homograft) operation results in biventricular circulation. Int J Cardiol. 2010;142:e45-47. DOI: 10.1016/j. ijcard.2008.11.185

19. Tanous D, Nadeem SN, Mason X, Colman JM, Benson LN, Horlick EM. Creation of a functional tricuspid valve: Novel use of percutaneously implanted valve in right atrial to right ventricular conduit in a patient with tricuspid atresia. Int J Cardiol. 2010;144:e8-10. DOI: 10.1016/j.ijcard.2008.12.034

20. Roberts $P$, Spina R, Vallely M, Wilson M, Bailey B, Celermajer DS, et al. Percutaneous tricuspid valve replacement for a stenosed bioprosthesis. Circ Cardiovasc Interv. 2010;3:e14-15. DOI: 10.1161/CIRCINTERVENTIONS.110.957555

21. Cerillo AG, Berti S, Glauber M. Transjugular tricuspid valve-in-valve implantation: $A$ safe and effective approach. Ann Thorac Surg. 2011;92:777-778. DOI: 10.1016/j. athoracsur.2010.12.015

22. Hon JKF, Cheung A, Ye J, Carere RG, Munt B, Josan $\mathrm{K}$, et al. Transatrial transcatheter tricuspid valve-in-valve implantation of balloon expandable bioprosthesis. Ann Thorac Surg. 2010;90: 1696-1697. DOI: 10.1016/j.athoracsur. 2010.04.101

23. Cullen MW, Cabalka AK, Alli O, Pislaru SV, Sorajja P, Nkomo VT, et al. Transvenous, antegrade melody valve-in-valve implantation for bioprosthetic mitral and tricuspid valve dysfunction: A case series in children and adults. J Am Coll Cardiol Interv. 2013;6:598-605. DOI: 10.1016/j. jcin.2013.02.010

24. Bentham J, Qureshi S, Eicken A, Gibbs J, Ballard G, Thomson J, et al. Early percutaneous valve failure within bioprosthetic tricuspid tissue valve replacements. Cathet Cardiovasc Interv. 2013;82:428-435. DOI: $10.1002 / \mathrm{ccd} .24622$

25. McElhinney DB, Cheatham JP, Jones TK, Lock JE, Vincent JA, Zahn EM. Stent fracture, valve failure, and right ventricular outflow tract reintervention after transcatheter pulmonary valve implantation:
Patient-related and procedural risk factors in the US Melody valve trial. Circ Cardiovasc Interv. 2011;4(6):602-614. DOI: 10.1161/ CIRCINTERVENTIONS.111.965616

26. Sanchez-Recalde A, Moreno R, Gonzalez A, Domínguez F, Leyra F, López-Sendón JL. Direct Percutaneous implantation of an Edwards-SAPIEN valve in tricuspid position in a degenerated bioprosthesis in a patient with Ebstein anomaly. Rev Esp Cardiol. 2014;67(9):769-780. DOI: 10.1016/j. rec.2014.03.013

27. Webb JG, Wood DA, Ye J, Gurvitch R, Masson JB, Rodés-Cabau J, et al. Transcatheter valve-in-valve implantation for failed bioprosthetic heart valves. Circulation. 2010;121:1848-1857. DOI: 10.1161/CIRCULATIONAHA.109.924613

28. Kempfert J, Blumenstein J, Chu MW, Pritzwald-Stegmann P, Kobilke T, Falk V, et al. Minimally invasive off-pump valve-in-aring implantation: The atrial transcatheter approach for re-operative mitral valve replacement after failed repair. Eur J Cardiothorac Surg. 2009;35:965-969. DOI: 10.1016/j.ejcts.2009.02.018

29. de Weger A, Ewe SH, Delgado V, Bax JJ. First-in-man implantation of a transcatheter aortic valve in a mitral annuloplasty ring: novel treatment modality for failed mitral valve repair. Eur J Cardiothorac Surg. 2011;39(6):1054-1056. DOI: 10.1016/j.ejcts.2010.09.021

30. Casselman F, Martens S, De Bruyne B, Degrieck I. Reducing operative mortality in valvular reoperations: the "valve in ring" procedure. J Thorac Cardiovasc Surg. 2011;141(5):1317-1318. DOI: 10.1016/j. jtcvs.2010.07.079

31. Mazzitelli D, Bleiziffer S, Noebauer C. Transatrial antegrade approach for double mitral and tricuspid "valve-in-ring" implantation. Ann Thorac Surg. 2013;95(1):e25-27. DOI: 10.1016/j.athoracsur.2012.09.092

32. Shuto $T$, Kondo N, Dori $Y$, Koomalsingh KJ, Glatz AC, Rome JJ, et al. Percutaneous transvenous Melody valve-in-ring procedure for mitral valve replacement. J Am Coll Cardiol. 2011;58(24):2475-2480. DOI: 10.1016/j.jacc.2011.09.021

33. Kondo N, Shuto T, McGarvey JR, Koomalsingh KJ, Takebe M, Gorman RC, et al. Melody valve-in-ring procedure for mitral valve replacement: feasibility in four annuloplasty types. Ann Thorac Surg. 2012;93(3):783788. DOI: 10.1016/j.athoracsur.2011.12.021

34. Lilly SM, Rome J, Anwaruddin S, Shreenivas S, Desai N, Silvestry FE, et al. How should I treat prosthetic tricuspid stenosis in an extreme surgical risk patient? Eurolntervention. 2013 Jul;9(3):407-409. DOI: 10.4244/ 
EIJV913A64

35. Fassa AA, Himbert D, Brochet E, Labbé JP, Vahanian A. Transfemoral valve-in-ring implantation for a failing mitral homograft in the tricuspid position. Eurolntervention. 2014;10(2):269. DOI: 10.4244/EIJV10I2A43

36. Boudjemline $Y$, Agnoletti G, Bonnet D, Behr $L$, Borenstein N, Sidi D, et al. Steps toward the percutaneous replacement of atrioventricular valves an experimental study. J Am Coll Cardiol. 2005;46(2):360-365. PMID: 16022968

37. Bai Y, Zong GJ, Wang HR, Jiang HB, Wang $\mathrm{H}, \mathrm{Wu} H$, et al. An integrated pericardial valved stent special for percutaneous tricuspid implantation: an animal feasibility study. J Surg Res. 2010;160(2):215-221. DOI: 10.1016/j.jss.2008.10.029

38. lino K, Lozonschi L, Metzner A, Marczynski-Bühlow M, Renner J, Cremer J, et al. Tricuspid valved stent implantation: novel stent with a self-expandable superabsorbent polymer. Eur J Cardiothorac Surg. 2011;40(2):503-507. DOI: 10.1016/j. ejcts.2010.11.051

39. Kefer J, Sluysmans T, Vanoverschelde JL. Transcatheter Sapien valve implantation in a native tricuspid valve after failed surgical repair. Catheter Cardiovasc Interv. 2014;83(5):841-845. DOI: 10.1002/ ccd. 25330

40. Lauten A, Figulla HR, Willich C, Laube A, Rademacher W, Schubert $\mathrm{H}$, et al. Percutaneous caval stent valve implantation: investigation of an interventional approach for treatment of tricuspid regurgitation. Eur Heart J. 2010;31:1274-1281. DOI: 10.1093/eurheartj/ehp474

41. Lauten A, Figulla HR, Willich $C$, Jung $C$, Rademacher $\mathrm{W}$, Schubert $\mathrm{H}$, et al. Heterotopic valve replacement as an interventional approach to tricuspid regurgitation.
J Am Coll Cardiol. 2010;55:499-500. DOI: 10.1016/j.jacc.2009.09.034

42. Lauten A, Ferrari $M$, Hekmat $K$, Pfeifer R, Dannberg G, Ragoschke-Schumm A, et al. Heterotopic transcatheter tricuspid valve implantation: first-in-man application of a novel approach to tricuspid regurgitation. Eur Heart J. 2011;32:1207-1213. DOI: 10.1093/eurheartj/ehr028

43. Lauten $A$, Hamadanchi A, Doenst T, Figulla HR. Caval valve implantation for treatment of tricuspid regurgitation: post-mortem evaluation after mid-term follow-up. Eur Heart J. 2014;35(25):1651. DOI: 10.1093/ eurheartj/eht471

44. Lauten A, Doenst T, Hamadanchi A, Franz $M$, Figulla HR. Percutaneous bicaval valve implantation for transcatheter treatment of tricuspid regurgitation clinical observations and 12-month follow-up. Circ Cardiovasc Interv. 2014;7:268-272. DOI: 10.1161/ CIRCINTERVENTIONS.113.001033

45. Laule M, Stangl V, Sanad W, Lembcke A, Baumann G, Stangl K. Percutaneous transfemoral management of severe secondary tricuspid regurgitation with Edwards Sapien XT bioprosthesis first-in-man experience. J Am Coll Cardiol. 2013;61(18):19291934. DOI: 10.1016/j.jacc.2013.01.070

46. Duerr GD, Endlich M, Sinning JM, Esmailzadeh B, Werner N, Mellert F, et al. Surgical banding of the inferior vena cava for the facilitation of transcatheter valve implantation in a patient with severe secondary tricuspid regurgitation. Eur Heart J. 2013;Dec 13. DOI: 10.1093/eurheartj/eht521

47. Taramasso $M$, Vanermen $H$, Maisano $F$, Guidotti A, La Canna G, Alfieri O. The growing clinical importance of secondary tricuspid regurgitation. J Am Coll Cardiol. 2012;59:703-710. DOI: 10.1016/j. jacc.2011.09.069
48. Agarwal S, Tuzcu EM, Rodriguez ER, Tan $\mathrm{CD}$, Rodriguez LL, Kapadia SR. Interventional cardiology perspective of functional tricuspid regurgitation. Circ Cardiovasc Interv. 2009;2:565-573. DOI: 10.1161/CIRCINTERVENTIONS.109.878983

49. Cohen SR, Sell JE, McIntosh CL, Clark RE. Tricuspid regurgitation in patients with acquired, chronic, pure mitral regurgitation, II: Nonoperative management, tricuspid valve annuloplasty, and tricuspid valve replacement. J Thorac Cardiovasc Surg. 1987;94:488-497. PMID: 3657251

50. Dreyfus GD, Corbi PJ, Chan KM, Bahrami T. Secondary tricuspid re-gurgitation or dilatation: which should be the criteria for surgical repair? Ann Thorac Surg. 2005;79:127-132. DOI: 10.1016/j.athoracsur.2004.06.057

Cite this article as: Jalal $Z$, Zegdi $R$, Lauten A, Mehul P, Boudjemline Y. Transcatheter Therapies for Tricuspid Valve Failure. Structural Heart Disease 2015;1(3):137-151. DOI: http://dx.doi. org/10.12945/j.jshd.2015.008.14 